\title{
Determination of Flicker Contribution Level by Using Proposed Index
}

\author{
Murat Silsupur, Belgin Emre Turkay \\ Department of Electrical Engineering, Istanbul Technical University, \\ Maslak-34469, Istanbul, Turkey \\ silsupur@itu.edu.tr
}

\begin{abstract}
Depending on different load characteristics, various power quality disturbances such as sag-swell, harmonics, inter-harmonics, and flicker, appear in electric power systems. Among these power quality disturbances, the flicker is one of the critical power quality phenomenon due to the lack of source detection and disturbance responsibility sharing method. The measurement of the flicker level is defined in the IEC 61000-4-15 standard by a flicker meter. This meter deals only with voltage signals and is not sufficient to understand the contribution of the load and background power systems separately. Thus, this paper proposes new approaches to the evaluation of flicker characteristics using the real on-site measurements taken from two different iron and steel factories. The novelty of this paper is investigating the flicker characteristics in light of statistical methods, spectral and multi-resolution wavelet analysis, and the information theory based wavelet energy entropy analysis together, and proposing a new index to interpret the flicker responsibility of load and power system. This proposed index is called Flicker Contribution Ratio (FCR) and represents the percentage flicker disturbance responsibility of both load and power system.
\end{abstract}

Index Terms-Flicker; Multi-resolution wavelet analysis; Spectral analysis; Wavelet energy entropy.

\section{INTRODUCTION}

Flicker is defined as the impression of unrest of visual affection caused by a light stimulus whose spectral distribution varies with time [1]. The light flicker or socalled voltage flicker appears because of the voltage fluctuation. Voltage flicker can be explained as voltage amplitude modulation, and its modulation frequency appears between $0.5 \mathrm{~Hz}$ to $35 \mathrm{~Hz}$.

Besides the conventional flicker generating sources such as arc furnaces and welding machines, wind turbines, solar power plants and variable frequency drives, are known as flicker sources. The frequency and the magnitude of the voltage fluctuation have great importance in term of the effect of each source on the flicker. The flicker level can be defined by a flicker meter depending on both the frequency and the magnitude.

The flicker level measurement is performed by a meter explained in the IEC 61000-4-15. The voltage signal is applied to the input of this meter and instantaneous flicker sensation $\left(\mathrm{P}_{\text {inst }}\right)$ and two discrete flicker severity indices called short term flicker $\left(\mathrm{P}_{\mathrm{st}}\right)$ and long term flicker $\left(\mathrm{P}_{\mathrm{lt}}\right)$ are

Manuscript received 29 November, 2017; accepted 2 March, 2018. obtained as outputs [2]. By considering $\mathrm{P}_{\mathrm{st}}$ and $\mathrm{P}_{\mathrm{tt}}$ values, the planning and compatibility levels of fluctuating installations for the flicker evaluation in the Medium Voltage (MV), High Voltage (HV), and Extra High Voltage (EHV) systems are defined in IEC 61000-3-7 [3] and IEEE 1453 [4].

The flicker measurement method in IEC 61000-4-15 is not sufficient to detect the aforementioned flicker sources precisely. Thus, various methods have been proposed in the literature for flicker source detection.

In [5] and [6], Axelberg et al. presented a flicker source detection method based on Flicker Power (FP) using the method in IEC 61000-4-15. In their method, both the voltage and current signals are processed in the flicker meter, and the FP is calculated. The method based on the sign and the magnitude of FP is suggested in [7].

A demodulation technique based on coherent phase detector is proposed by Poormonfaredazimi et al. [8] for FP calculation. Jamaludin et al. proposed a new Fast Fourier Transform based demodulation technique [9] and [10]. An energy method for flicker source determination is introduced in [11]. The sign of flicker energy is positive, when the flow direction is downstream and vice versa.

Shao et al developed a flicker disturbance responsibility method using a voltage signal at the Point of Common Coupling (PCC) [12]. The calculated voltage values at the PCC are processed as inputs of the IEC flicker meter, and the flicker disturbance responsibility for each load is obtained. In this method, only a one load impedance is assumed a fluctuating load for a period of time while the other loads are assumed as non-fluctuating. A similar method is given in IEEE 1453 for the flicker contribution estimation of a single load. This method requires knowing the source impedance, and assumes that this impedance and source open circuit voltage are constant.

A flicker contribution method using reactive currents of electrical arc furnaces (EAF) is suggested by the authors in [13]. Using individual reactive current components and power system source impedance, voltage drop is obtained then this voltage value is applied the IEC flicker meter. The short term flicker values for each EAF are calculated and then flicker responsibility of each individual EAF is obtained. In this method, individual load currents at the same busbar are measured. But, the flicker sources might be distributed in power systems and this case is not investigated.

Nassif et al. developed a new flicker source identification 
method based on V-I slope curve [14]. The sign of the slope gives information about the source location. The sign of the slope is positive, when the flow direction is downstream.

In [15] and [16], theoretical assessment of flicker caused by Variable Frequency Drive (VFD) is presented. The authors also propose to determine the location of source by considering the interharmonic power.

The wavelet representation of voltage flicker is presented in [17] and [18]. In these papers, flicker calculation and assessment are proposed using Multi Resolution Wavelet Analysis [MRA]. In order to get more accurate flicker and harmonic measurement and to prevent the leakage effect of the FFT algorithm, the authors suggested a hybrid algorithm by using FFT and Wavelet Transform [19]. In [20], the authors developed a flicker measurement method based on Orthogonal Hilbert Huang Transform.

As seen from the previous papers, the main purpose is detecting the flicker source rather than interpreting the contribution of each load and remaining power system separately. The aforementioned proposed methods with some assumptions are not applicable for all the circumstances in the real power systems. Therefore, in order to get a better understanding of the individual flicker responsibility, it is necessary to perform a comprehensive flicker analysis. For this purpose, the flicker characteristics of the electric arc furnace (EAF) and ladle furnace (LF) are investigated in this paper by using statistical methods, spectral analysis, and multi-resolution wavelet analysis.

The novelty of this paper is investigating the flicker characteristics in the flicker frequency range by using the above mentioned analysis methods together which is not applied before, and proposing new approaches as well as a new index for evaluation. The main contribution to the scientific knowledge is introducing a method for determination of flicker contribution level by using multiresolution wavelet analysis, and wavelet energy entropy analysis together. Unlike Fourier Transform, Wavelet Transform can locate the changes in the signal and the analysis of the signal in both time domain and frequency domain can be easily achieved. With the help of multiresolution wavelet analysis, the signal can be decomposed in different levels and the reflection of the energy distribution of signal and the information about any change of the signal in the time domain can be obtained accordingly. In a case of a disturbance, magnitude and frequency of the signal will change and it will result a change in entropy as well. Since flicker is described as a power quality disturbance with an amplitude modulation with a modulation frequency, in order to determine flicker contribution of the load, multiresolution wavelet analysis based wavelet energy entropy method is used in this work. Wavelet decomposition of signal is performed to calculate the wavelet energy distribution at each decomposition level and the results are used for entropy calculation. Thus, flicker contribution of the load is obtained using wavelet entropy values.

\section{Mathematical Methods}

\section{A. Calculation of Statistical Parameters}

Statistical calculations of time series data give useful information for analysis. In order to define some properties of a discrete time series signal, several statistical parameters are used. The mean value and the standard deviation are mainly used to define the properties of the time series data. Let $x_{i}$ be a date set, and then the mean value and the standard deviation are described in (1) and (2), respectively:

$$
\begin{gathered}
\mu=\frac{1}{N} \sum_{i=1}^{N} x_{i}, \\
\sigma=\sqrt{\frac{1}{N} \sum_{i=1}^{N}\left(x_{i}-\mu\right)^{2}},
\end{gathered}
$$

where $N$ is the number of data.

There are two additional parameters for statistical analysis called skewness and kurtosis. Skewness can be as a measure of the asymmetry of the data set around a mean. Kurtosis is a parameter which gives information about the shape of the distribution of the data series [21]. These two parameters are calculated as follows:

$$
\begin{gathered}
\alpha=\frac{\left[\frac{1}{N} \sum_{i=1}^{N}\left(x_{i}-\mu\right)^{3}\right]}{\sigma^{3}}, \\
\beta=\frac{\left[\frac{1}{N} \sum_{i=1}^{N}\left(x_{i}-\mu\right)^{4}\right]}{\sigma^{4}},
\end{gathered}
$$

where $\alpha$ is skewness and $\beta$ is kurtosis.

For a normal distribution, skewness equates to zero and kurtosis equates to three. Positive skewness indicates that most values are located on the left side of the mean, and negative skewness indicates that most values are located on the right side of the mean. The above mentioned parameters are used to investigate the statistical characteristics of a signal [22].

\section{B. Short-Time Fourier Transform (STFT)}

The Fourier transform analysis cannot give any information about the time-localization characteristic of a signal. Normally, the majority of the signals are not stationary and their frequency changes with time. The FT is not suitable to analyze such kinds of signals and a hybrid time-frequency representation is required to describe the characteristics of the signal. For this purpose, Gabor introduced the special application of FT called Windowed Fourier Transform in order to measure localized frequency components of sounds. This method is called Gabor Transform and it provides a joint time-frequency representation of a given signal [23]. STFT is a special form of Gabor Transform and it is a useful tool to describe the important characteristics of a given signal.

STFT can be calculated for continuous as well discrete time signals. For a continuous signal, STFT is defined in the following equation

$$
S(t, f)=\int_{-\infty}^{\infty} s(\tau) h(t-\tau) e^{-j \omega \tau} d \tau,
$$

where $h(t-\tau)$ is the analysis window function. 
The energy distribution, known as the spectrogram, is used to estimate the power spectrum of a signal. The spectrogram can be defined as follows

$$
|S(t, f)|^{2}=\left|\int_{-\infty}^{+\infty} s(\tau) h(t-\tau) e^{-j \omega \tau} d \tau\right|^{2}
$$

where $h(t-\tau)$ is the even time-limiting analysis window, centered at $\tau$, and is referred to the short-time Fourier transform (STFT). The time-frequency characteristic of the spectrogram is given by its display of the signal as a function of the frequency, $f$, and the window center time [24].

\section{Multi-Resolution Wavelet Analysis (MRWA)}

As stated in section B, STFT analysis takes care of the joint time-frequency behavior of signals and this method may not be sufficient for non-stationary signal analysis. Wavelet Transform may be used to analyse such kinds of signals and provide a good time-scale representation. In wavelet analysis, a special function called wavelet is chosen and the wavelet representation of the signal is obtained by further processing of this wavelet function [25].

Wavelet transform is expressed in (5) as dilations and translations of mother wavelet $\Psi(t)$

$$
W_{x}(a, b)=\int_{-\infty}^{+\infty} x(t) \Psi_{a, b}^{*}(t) d t
$$

where $a$ and $b$ are scaling and shifting parameters, respectively. By shifting and scaling the mother wavelet, daughter wavelets are calculated as follows

$$
\Psi_{a, b}(t)=\frac{1}{\sqrt{a}} \Psi\left(\frac{t-b}{a}\right) .
$$

If the scaling and the shifting parameters are presented as $a=a_{0}^{m}$ and $b=n b_{0} a_{0}^{m}$, the discrete wavelet transform (DWT) is obtained in (7)

$$
\operatorname{DWTx}(m, n)=\sum x(k) \Psi_{m, n}(k),
$$

where $m, n \in Z, \quad a_{0}>1$ and $b_{0}>1$. Discrete mother wavelet $\Psi_{m, n}(k)$ is stated as follows

$$
\Psi_{m, n}(k)=\frac{1}{\sqrt{a_{0}^{m}}} \Psi\left(\frac{k-n b_{0} a_{0}^{m}}{a_{0}^{m}}\right) .
$$

An algorithm called as Multi-Resolution Analysis (MRA) is introduced by Mallat to perform Discrete Wavelet Transform [26]. In MRA, the signal is decomposed using low-pass and high-pass filters and sub-bands are obtained. The low frequency sub-band components are termed as approximations, $\mathrm{Ca}_{\mathrm{i}}$ and high frequency sub-band components are termed as details, $\mathrm{Cd}_{\mathrm{i}}$.

\section{Wavelet Energy Entropy}

The wavelet energy entropy (WEE) is expressed as a combination of Shannon's information entropy and wavelet transform. By using Multi-resolution Wavelet Analysis, the wavelet energy of $j$ decomposition scale is calculated in (9)

$$
E_{j}=\sum_{k}^{N}\left|D_{j}(k)\right|^{2},
$$

where $D_{j}(k)$ refers to coefficients of $j$ decomposition scale. The energy of the signal and the distribution of the energy can be defined as follows:

$$
\begin{gathered}
E=\sum_{j=1}^{m} E_{J}, \\
p_{j}=\frac{E_{j}}{E} .
\end{gathered}
$$

Wavelet Energy Entropy (WEE) is obtained as in (12)

$$
W E E=-\sum_{i=1}^{n} p_{j} \log _{2} p_{j} .
$$

The WEE measures the energy of the wavelet coefficients at each decomposition scale, and gives the energy distribution of the signal. If different frequency components appear in the content of the signal, higher WEE values are obtained [27]. The unit of WEE is bits since the base of the logarithm is chosen as 2 .

\section{MeAsurements AND APPliCATION OF THE MEthods}

On-site measurements were performed in two different iron and steel factories in the south Marmara region in Turkey. The first factory has one LF which is a size of $7 \mathrm{MVA}$ and two induction furnace (IF) each one is 12MVA. During measurement only one IF was operating. The second factory has 2 LFs each one is 11 MVA and one EAF which has a capacity of $50 \mathrm{MVA}$. In this paper, these factories are called as BDC and ASC, respectively. Both factories are supplied with $34.5 \mathrm{kV}, 50 \mathrm{~Hz}$ feeder from $154 / 34.5 \mathrm{kV}$ substation and measurements were performed at the point of common coupling.

The measurements were carried out with IEC 61000-4-30 Class A power quality recorder whose sampling frequency is $40960 \mathrm{~Hz}$. Such a high sampling frequency is suitable considering the high frequency components in the measurements due to the operating characteristics of the existing SVC system. The power quality recorder has three voltage and three current inputs. Voltage signals are received from the secondary side of voltage transformer with rating $34.5 \mathrm{kV} / 0.1 \mathrm{kV}$ and current signals are received the secondary side of current transformer with rating 1250/5 A and 2000/5 A from the factories BDC and ASC, respectively. The connection diagram of the power quality recorder is given in Fig. 1.

Three different cases were measured as Off State, On State, and Start State, with a period of 4 seconds means 
163840 samples. Off State means there is no load, On State means EAF, LFs and IFs are operating at full load, and Start State means the transition from the Off State to the On State. An Off state measurement is used to obtain a background flicker effect, while an On State measurement is used to obtain the flicker responsibility of the load. A Start state measurement is used to visualize the load's flicker effect.

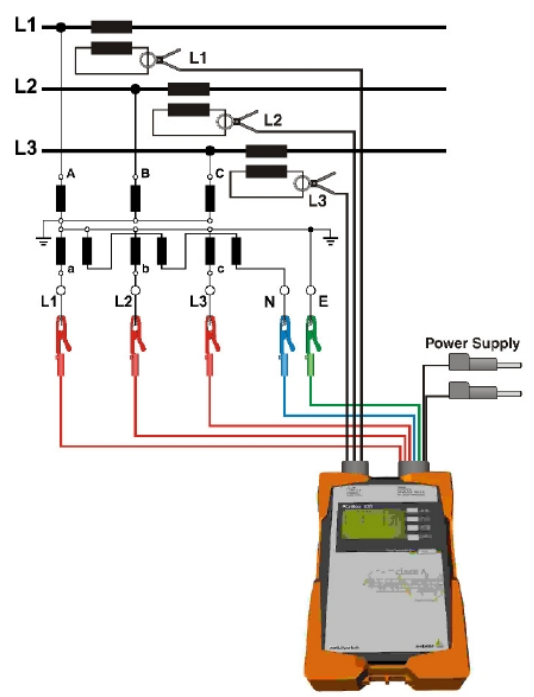

Fig. 1. Connection diagram of power quality recorder.

First, the measurements of the BDC were investigated. In the following figures (Fig. 2 to Fig. 6), the Off State voltages, the On State voltages and currents, and the Start State voltages and currents are given in periods of 4 seconds. When the load is operating, the voltage amplitude modulation is clearly seen in Fig. 3 when compared to Fig. 2. The Start State voltage and current waveforms are given in Fig. 5 and Fig. 6, in order to visualize the effect of the load to voltage modulation.

The amplitude modulation of the voltage is seen clearly in Fig. 3 in comparison to Fig. 2. The amplification in the voltage signal is also expressed via the Short-Term Flicker values for the Off and On State in the following figure.

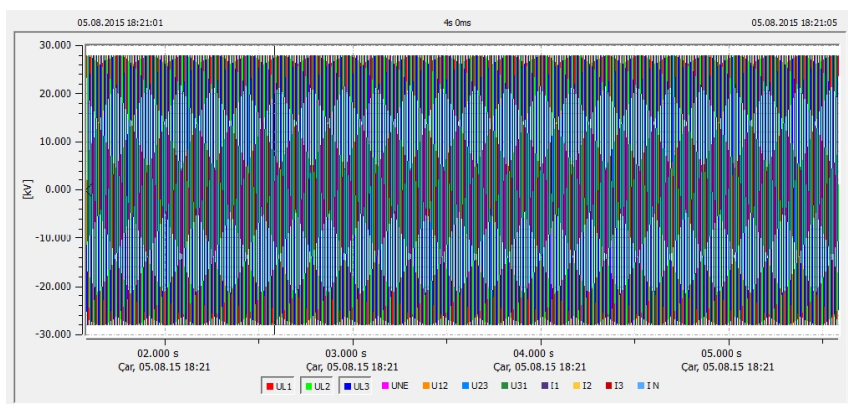

Fig. 2. BDC off state voltages -4 seconds.

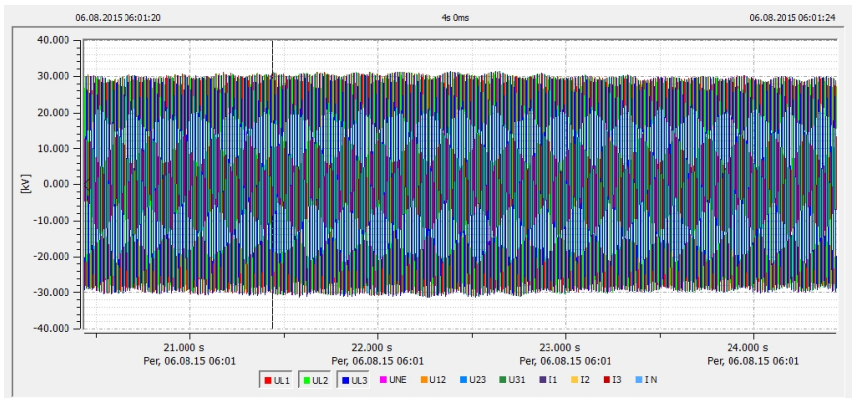

Fig. 3. BDC on state voltages -4 seconds.

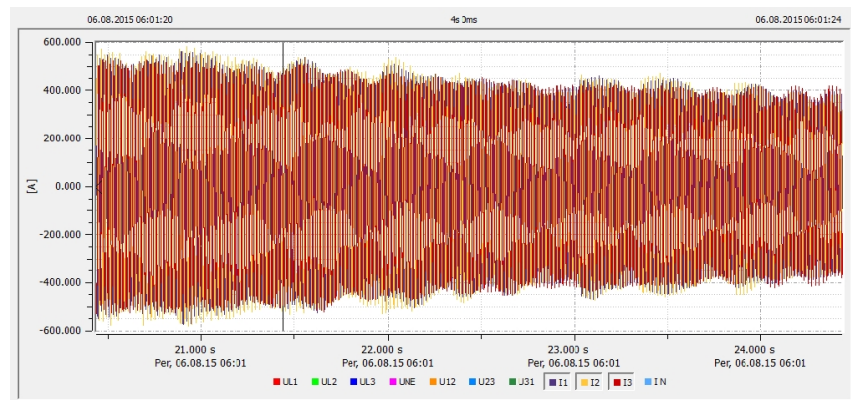

Fig. 4. BDC on state currents -4 sec.

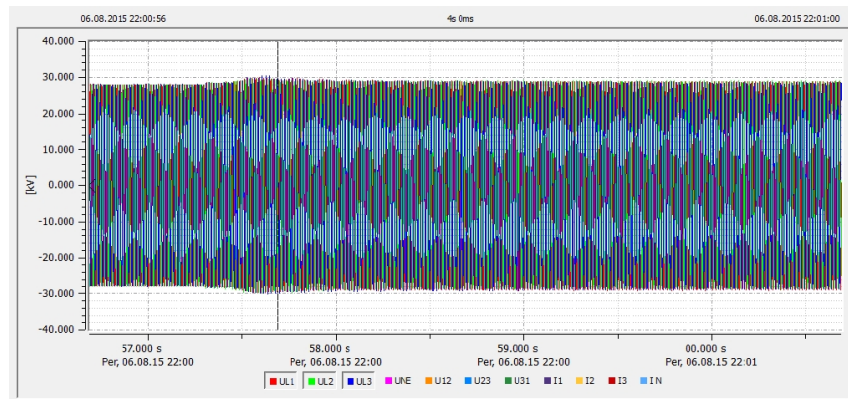

Fig. 5. BDC start state voltages -4 seconds.

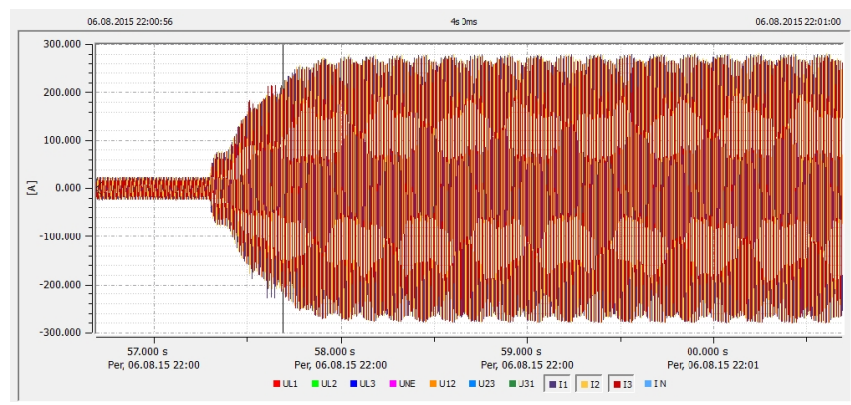

Fig. 6. BDC start state currents -4 seconds.

Fig. 7 shows the $\mathrm{P}_{\text {st }}$ values measured over a period of ten minutes with a duration of 12 hours and 40 minutes.

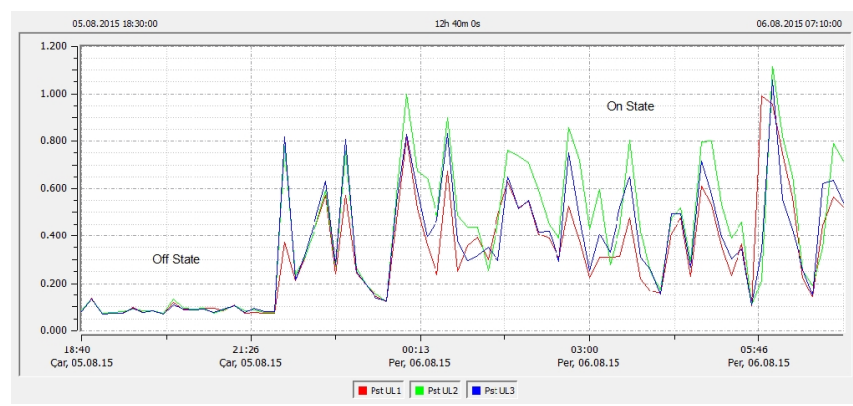

Fig. 7. BDC - Pst values for off and on state.

Then, the measurements of the ASC were investigated. In the following figures (Fig. 8 to Fig 12), the Off State voltages, the On State voltage and currents, and the Start State voltages and currents are given in periods of 4 seconds.

The voltage amplitude modulation due to the EAF and LFs is more visible in Fig. 9 when compared to Fig. 8. The nonlinear characteristics of the EAF and LFs can be seen in Fig. 10. The Start State voltage and the current waveforms are given in Fig. 11 and Fig. 12, in order to visualize the effect of the load to voltage modulation.

Since the main load in the ASC is EAF, the amplitude modulation of the voltage is seen more clearly in Fig. 9 when compared to Fig. 8. The amplification in the voltage 
signal is also shown in the $\mathrm{P}_{\mathrm{st}}$ values as given in Fig. 13. These $\mathrm{P}_{\text {st }}$ values were measured over a period of ten minutes in a duration of 3 hours.

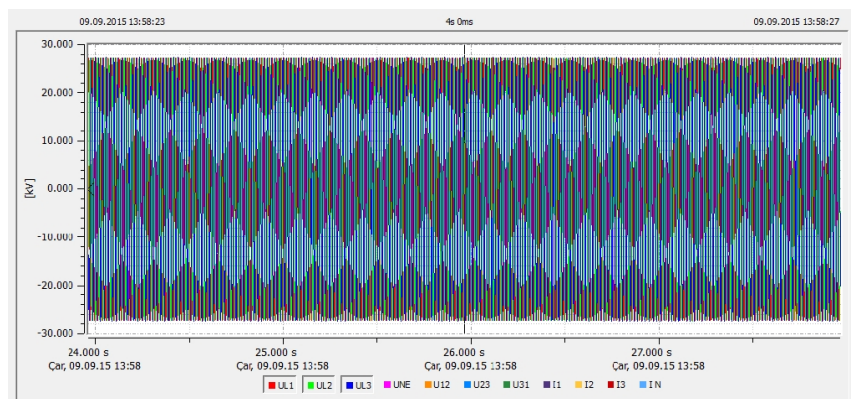

Fig. 8. ASC off state voltages -4 seconds.

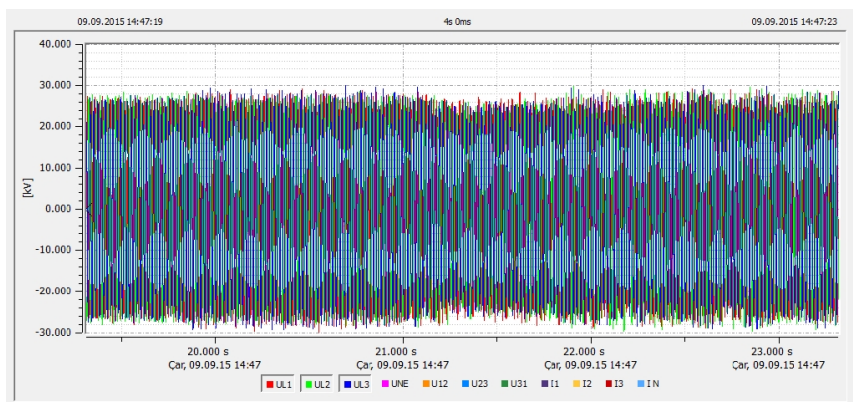

Fig. 9. ASC on state voltages -4 seconds.

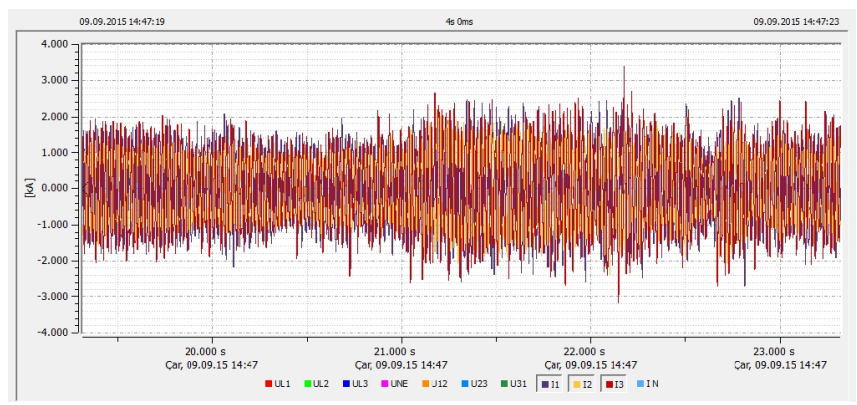

Fig. 10. ASC on state currents -4 seconds.

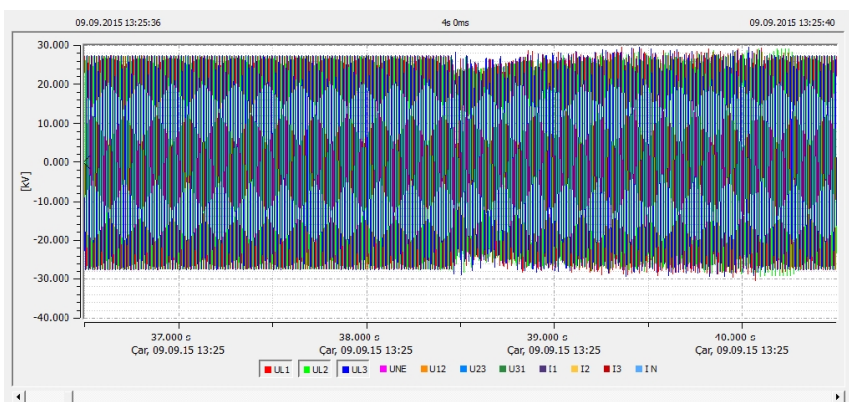

Fig. 11. ASC start state voltages -4 seconds.

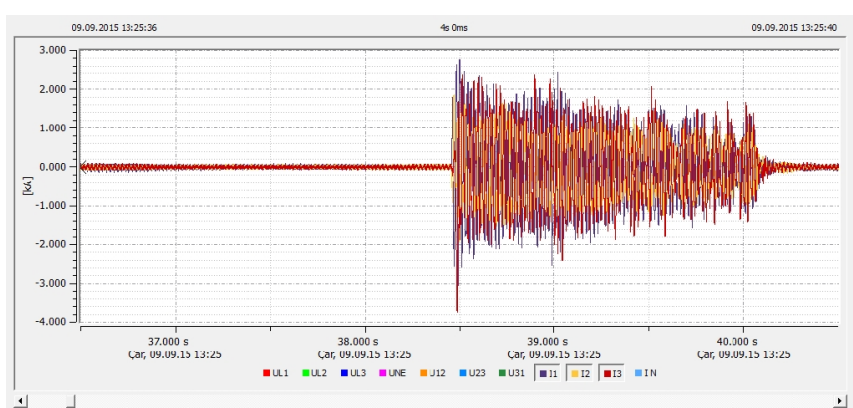

Fig. 12. ASC start state currents -4 seconds.

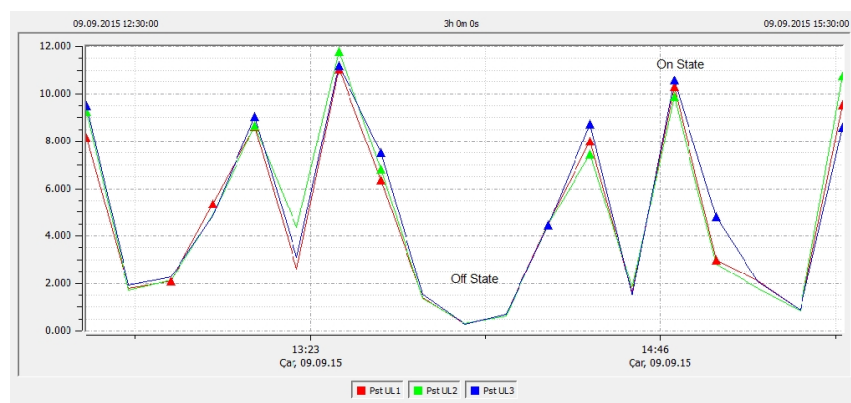

Fig. 13. ASC - Pst values for off and on state.

\section{A. Statistical Analysis}

According to the statistical calculations given in Section II, the aforementioned statistical parameters are calculated for both the On and Off State by using the data that belongs to the sampled voltage values of Phase L1. The results are given in the Table I and Table II.

TABLE I. STATISTICAL PARAMETERS FOR BDC.

\begin{tabular}{|c|c|c|c|c|c|}
\hline & Mean & Variance & Std & Skewness & Kurtosis \\
\hline UL1_Off & 80.3636 & 292.8545 & 17.1130 & -0.2417 & 2.0475 \\
\hline UL1_On & 79 & 316.8889 & 17.8014 & 0.1228 & 2.3727 \\
\hline
\end{tabular}

TABLE II. STATISTICAL PARAMETERS FOR ASC.

\begin{tabular}{|c|c|c|c|c|c|}
\hline & Mean & Variance & Std & Skewness & Kurtosis \\
\hline UL1_Off & 81.6364 & 279.4545 & 16.7169 & -0.4717 & 2.3465 \\
\hline UL1_On & 80.4000 & 306.0444 & 17.4941 & -0.1057 & 2.5307 \\
\hline
\end{tabular}

Asymmetrical distribution and its measurement called a Signal to Noise Ratio can be defined by using the results in Table I and Table II for On and Off State as follows:

$$
\begin{aligned}
& S N R=\frac{\sigma_{B D C \_U L 1 \_O f f}^{2}}{\sigma_{B D C \_U L 1 \_O n}^{2}}=0.9242, \\
& S N R=\frac{\sigma_{A S C \_U L 1 \_O f f}^{2}}{\sigma_{A S C \_U L 1 \_O n}^{2}}=0.9131 .
\end{aligned}
$$

In (13) and (14), Off State and On State are interpreted as the Signal and Noise, respectively. Due to the operating characteristics of the EAF, the distribution of the time series data of the ASC is more asymmetrical in On State when compared to the time series data of the BDC. Hence, the calculated SNR value of the ASC in (14) is smaller than the calculated SNR value of the BDC in (13) as expected.

\section{B. Spectral Analysis}

The spectral analyses of the signals are performed by using Fast Fourier Transform in order to estimate Power Spectral Density (PSD). In Fig. 14 and Fig. 15, is given the PSD of the data which belongs to sampled voltage values of Phase L1 for both BDC and ASC. The blue dotted line shows the Off State and the red line shows the On State. In the figures, the frequency range is shown from $0 \mathrm{~Hz}$ to $45 \mathrm{~Hz}$.

The variation of the flicker frequency components in the ASC is more visible than the BDC. This is due to the dominant flicker source being EAF in ASC. Due to the nonlinear fluctuating current characteristics of the EAF, it 
generates more voltage fluctuations and flicker frequency components at the PCC.

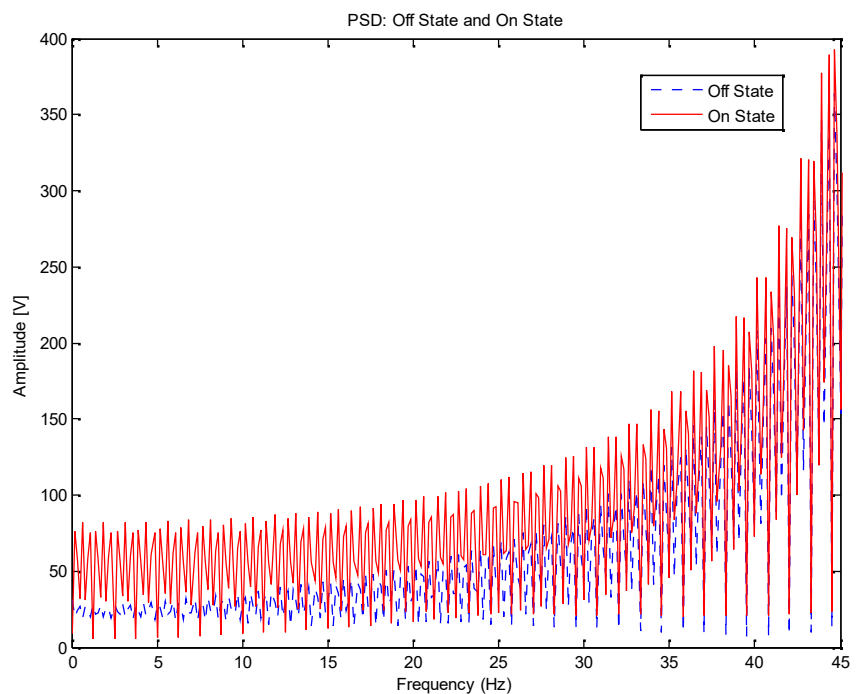

Fig. 14. BDC - spectral comparison of off and on state.

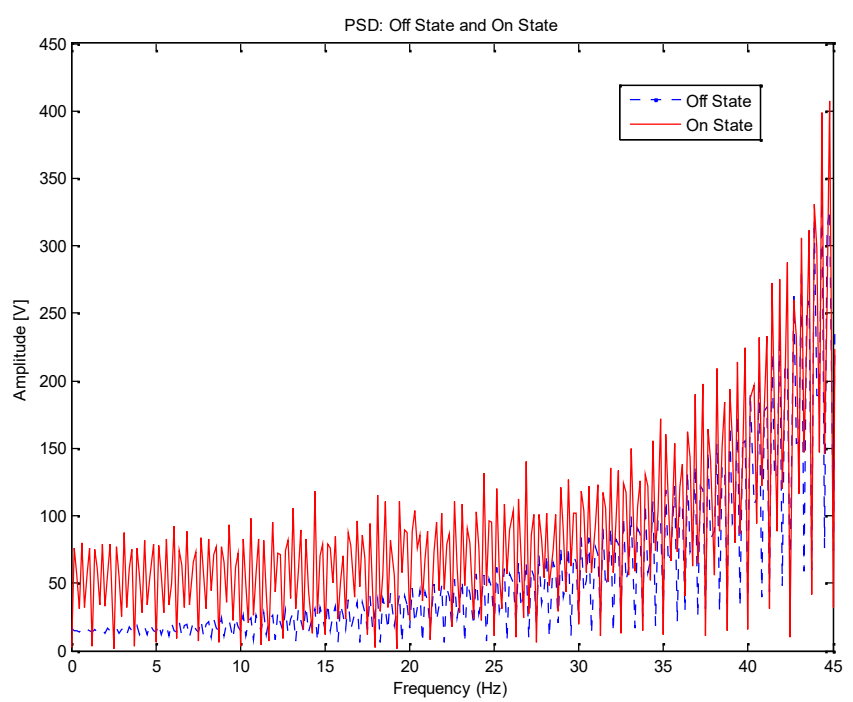

Fig. 15. ASC - spectral comparison of off and on state.

The energy distribution, or in other words, the spectrogram, is created in order to estimate the power spectrum of the signals. The spectrograms are generated by using the sampled voltage values of Phase L1 and are given in Fig. 16 and Fig. 17.

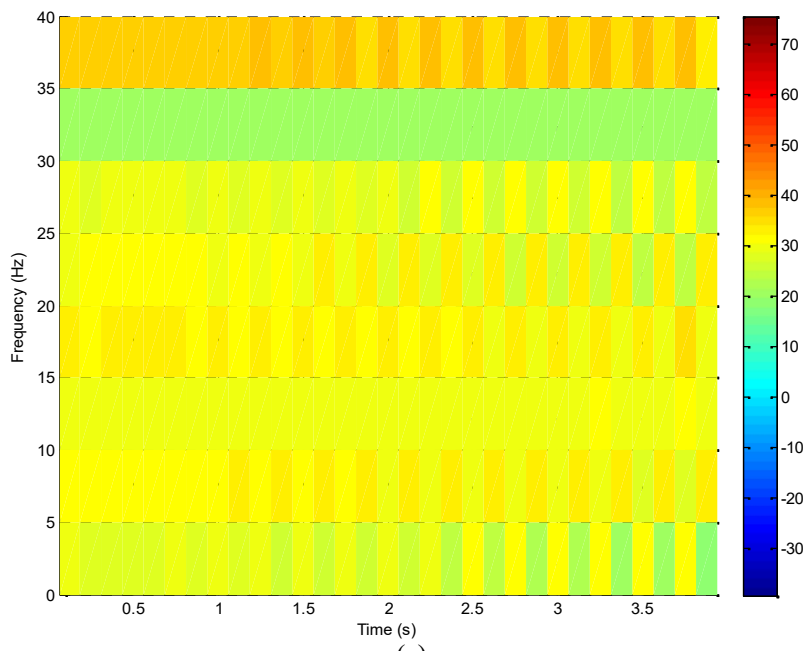

(a)

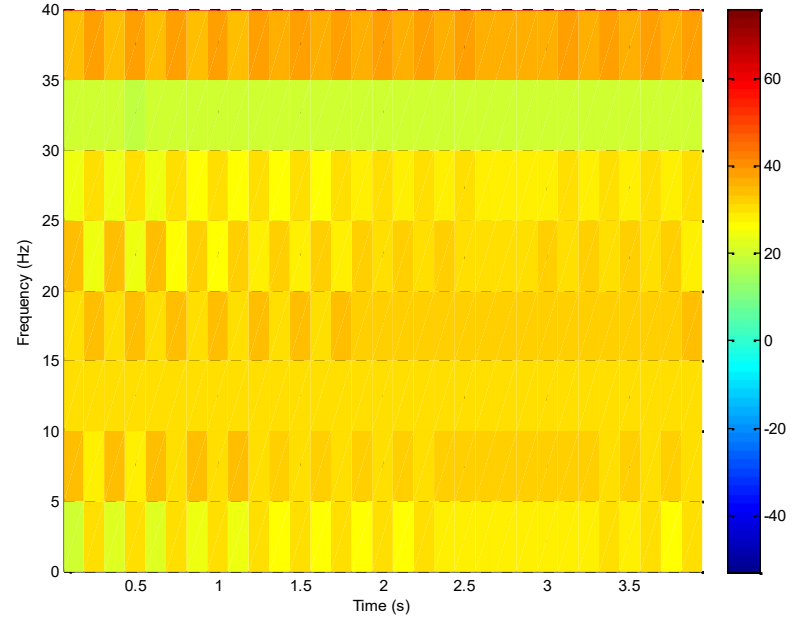

(b)

Fig. 16. BDC - spectrogram for off (a) and on (b) state.

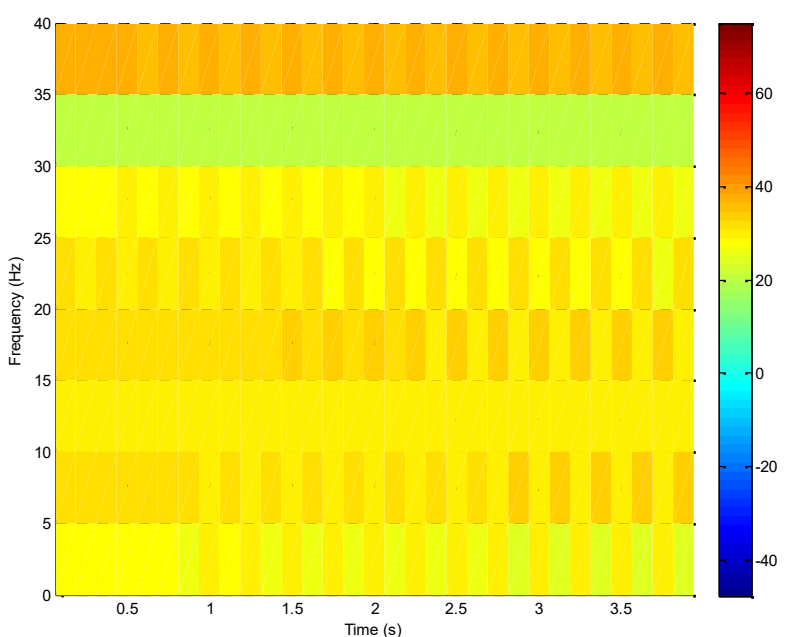

(a)

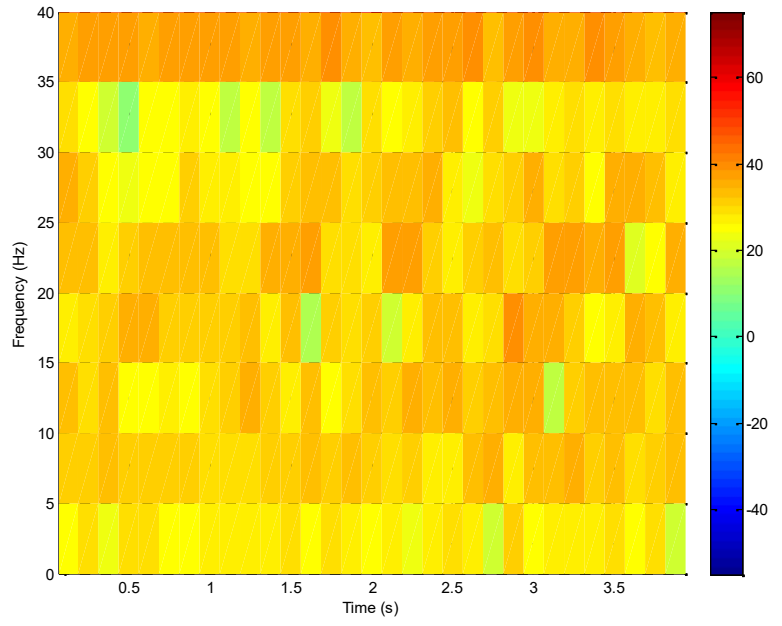

(b)

Fig. 17. ASC - spectrogram for off (a) and on (b)state

Since, the EAF, LFs and IFs, are operating on full load during the On State, more components appear in the flicker frequency range accordingly. Thus, the higher amplitudes in the flicker frequency range during the On State are more visible when compared to the Off State in the spectrograms.

\section{Multi Resolution Wavelet Analysis}

In wavelet analysis, various wavelets functions such as Haar, Morlet, Coiflet, Symlet and Daubechies are used. In power quality applications, Daubechies wavelets with the order 4 is the most widely employed [28]. Since the flicker 
frequency range is $0 \mathrm{~Hz}$ to $35 \mathrm{~Hz}$ and the frequency band of $9^{\text {th }}$ decomposition corresponds to $0 \mathrm{~Hz}$ to $40 \mathrm{~Hz}$, the level of decomposition is chosen as 9 . The nine level decomposition provides the information regarding the flicker components of the signal without losing any data. Table III shows the 9level frequency sub-bands. In this paper, the analysis of the signals was fulfilled by the MATLAB Wavelet Toolbox and the 9-level MRA was performed by using the $\mathrm{db} 4$ wavelet.

TABLE III. FREQUENCY SUB-BANDS OF MRA.

\begin{tabular}{|c|c|c|c|}
\hline Approximations & Sub-bands (Hz) & Details & Sub-bands (Hz) \\
\hline $\mathrm{Ca} 1$ & $0-10240$ & $\mathrm{Cd} 1$ & $10240-20480$ \\
\hline $\mathrm{Ca} 2$ & $0-5120$ & $\mathrm{Cd} 2$ & $5120-10240$ \\
\hline $\mathrm{Ca} 3$ & $0-2560$ & $\mathrm{Cd} 3$ & $2560-5120$ \\
\hline $\mathrm{Ca} 4$ & $0-1280$ & $\mathrm{Cd} 4$ & $1280-2560$ \\
\hline $\mathrm{Ca} 5$ & $0-640$ & $\mathrm{Cd} 5$ & $640-1280$ \\
\hline $\mathrm{Ca} 6$ & $0-320$ & $\mathrm{Cd} 6$ & $320-640$ \\
\hline $\mathrm{Ca} 7$ & $0-160$ & $\mathrm{Cd} 7$ & $160-320$ \\
\hline $\mathrm{Ca} 8$ & $0-80$ & $\mathrm{Cd} 8$ & $80-160$ \\
\hline $\mathrm{Ca} 9$ & $0-40$ & $\mathrm{Cd} 9$ & $40-80$ \\
\hline
\end{tabular}

In the analysis, the sampled voltage values of the Phase L1 for both the BDC and ASC are used. By using the MRA, the ninth approximations for the Off and On State are extracted, and are used for further calculations.

According to the statistical calculations given in Section II, the statistical parameters are calculated for the On and Off State by using the ninth approximations obtained from the sampled voltage values of Phase L1. The results are given in Table IV and Table V.

TABLE IV. STATISTICAL PARAMETERS OF APPROXIMATIONS FOR BDC.

\begin{tabular}{|c|c|c|c|c|c|}
\hline & Mean & Variance & Std & Skewness & Kurtosis \\
\hline UL1_Off & 79.600 & 297.8222 & 17.2575 & 0.2063 & 1.3917 \\
\hline UL1_On & 78 & 322.1742 & 17.9513 & 0.6206 & 2.0097 \\
\hline
\end{tabular}

TABLE V. STATISTICAL PARAMETERS OF APPROXIMATIONS FOR ASC.

\begin{tabular}{|c|c|c|c|c|c|}
\hline & Mean & Variance & Std & Skewness & Kurtosis \\
\hline UL1_Off & 81.0000 & 285.1111 & 16.8852 & -0.0182 & 1.4688 \\
\hline UL1_On & 79.5556 & 313.2778 & 17.6997 & 0.38277 & 1.9293 \\
\hline
\end{tabular}

The SNR is calculated for the values given in Table IV and Table V:

$$
\begin{gathered}
S N R=\frac{\sigma_{B D C_{-} O f f_{-} A 9}^{2}}{\sigma_{B D C_{-} O n_{-} A 9}^{2}}=0.9242, \\
S N R=\frac{\sigma_{A S C_{-} O f f_{-} A 9}^{2}}{\sigma_{A S C_{-} O n_{-} A 9}^{2}}=0.91 .
\end{gathered}
$$

As seen from the results in (15) and (16), the SNR values calculated by the ninth approximations are identical to the SNR values of the main signal obtained in (13) and (14). The results prove that the wavelet coefficients corresponding to the flicker frequency range could be used to identify the characteristics of the flicker.

In order to interpret the flicker level contribution of the load and remaining power systems separately, the correlation between the fluctuating current signal and the voltage signal must be obtained. Thus, it would be better to process the current signals as well. For that reason, the MRA is performed by using the sampled current values of
Phase L1. The ninth approximations of the current signals are extracted. The PSDs of the ninth level current approximations are given in Fig. 18 and Fig. 19. The flicker frequency components are more visible in Fig. 19 due to the operating characteristics of the EAF in ASC.

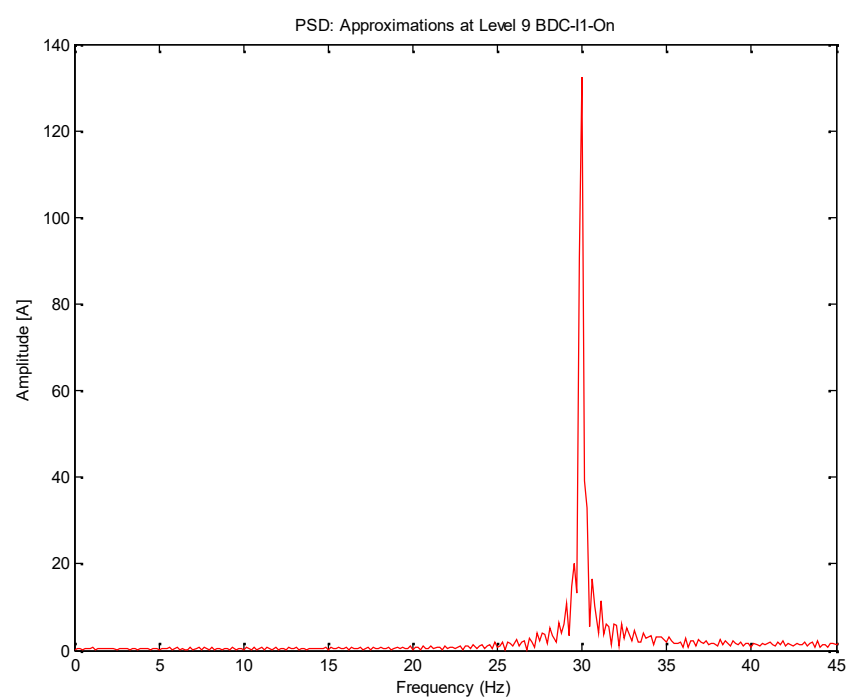

Fig. 18. BDC - PSD of current approximations.

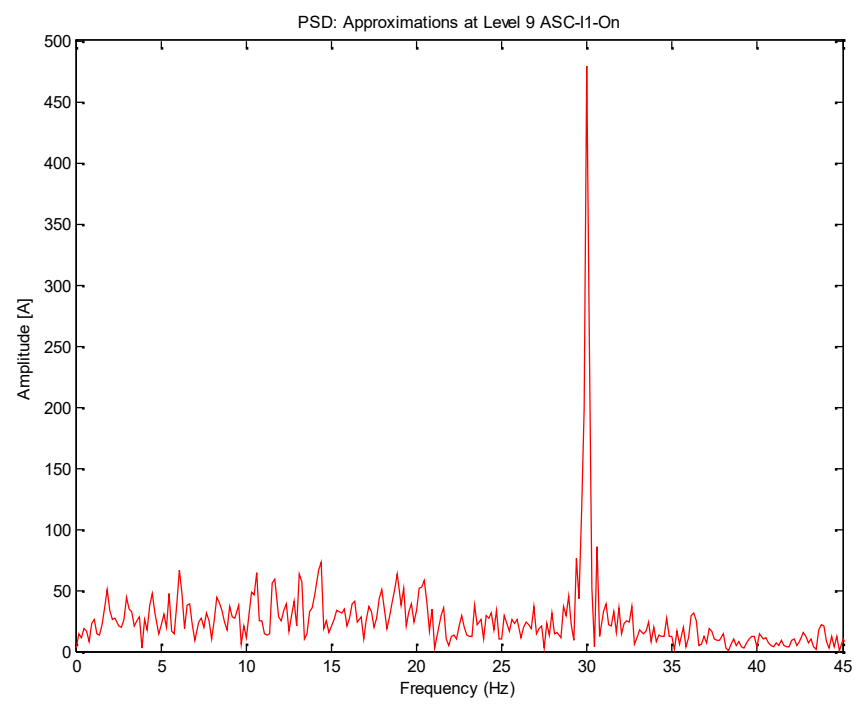

Fig. 19. ASC - PSD of current approximations.

\section{Wavelet Energy Entropy Calculation}

As explained in Section II, the WEE values are calculated for the OFF state voltage signal, the ON state voltage signal, and the ON state current signal. The wavelet energy values and energy distribution values are given in the following tables.

TABLE VI. BDC - WAVELET ENERGY VALUES (E $\mathrm{E}_{\mathrm{T}}$ ).

\begin{tabular}{|c|c|c|c|}
\hline $\begin{array}{c}\text { Decomposition } \\
\text { Scale }\end{array}$ & $\begin{array}{c}\text { OFF State } \\
\text { Voltage }\end{array}$ & $\begin{array}{c}\text { ON State } \\
\text { Voltage }\end{array}$ & $\begin{array}{c}\text { ON State } \\
\text { Current }\end{array}$ \\
\hline 1 & $4,44 \mathrm{E}-07$ & $5,95 \mathrm{E}-05$ & $1,52 \mathrm{E}-04$ \\
\hline 2 & $9,35 \mathrm{E}-07$ & 0,004238 & $3,67 \mathrm{E}-04$ \\
\hline 3 & $2,18 \mathrm{E}-05$ & 0,097516 & 0,001856 \\
\hline 4 & 0,000110403 & 0,058656 & 0,00639 \\
\hline 5 & 0,000168322 & 0,021395 & 0,099097 \\
\hline 6 & 0,00186625 & 0,079936 & 0,566428 \\
\hline 7 & 0,041265212 & 0,044563 & 0,098366 \\
\hline 8 & 4,579089834 & 4,730026 & 4,653352 \\
\hline 9 & 78,89561521 & 81,22726 & 79,69836 \\
\hline
\end{tabular}


TABLE VII. BDC - ENERGY DISTRIBUTION VALUES ( $\mathrm{P}_{\mathrm{I}}$.

\begin{tabular}{|c|c|c|c|}
\hline $\begin{array}{c}\text { Decomposition } \\
\text { Scale }\end{array}$ & $\begin{array}{c}\text { OFF State } \\
\text { Voltage }\end{array}$ & $\begin{array}{c}\text { ON State } \\
\text { Voltage }\end{array}$ & $\begin{array}{c}\text { ON State } \\
\text { Current }\end{array}$ \\
\hline 1 & $5,31992 \mathrm{E}-09$ & $6,9 \mathrm{E}-07$ & $1,78 \mathrm{E}-06$ \\
\hline 2 & $1,1192 \mathrm{E}-08$ & $4,91 \mathrm{E}-05$ & $4,31 \mathrm{E}-06$ \\
\hline 3 & $2,61044 \mathrm{E}-07$ & 0,00113 & $2,18 \mathrm{E}-05$ \\
\hline 4 & $1,32191 \mathrm{E}-06$ & 0,00068 & $7,51 \mathrm{E}-05$ \\
\hline 5 & $2,0154 \mathrm{E}-06$ & 0,000248 & 0,001164 \\
\hline 6 & $2,23455 \mathrm{E}-05$ & 0,000927 & 0,006654 \\
\hline 7 & 0,000494087 & 0,000517 & 0,001156 \\
\hline 8 & 0,054827489 & 0,054832 & 0,054665 \\
\hline 9 & 0,944652464 & 0,941616 & 0,936258 \\
\hline
\end{tabular}

TABLE VIII. ASC - WAVELET ENERGY VALUES $\left(\mathrm{E}_{\mathrm{I}}\right)$.

\begin{tabular}{|c|c|c|c|}
\hline $\begin{array}{c}\text { Decomposition } \\
\text { Scale }\end{array}$ & $\begin{array}{c}\text { OFF State } \\
\text { Voltage }\end{array}$ & $\begin{array}{c}\text { ON State } \\
\text { Voltage }\end{array}$ & $\begin{array}{c}\text { ON State } \\
\text { Current }\end{array}$ \\
\hline 1 & 0.0001 & 0.0001 & $6.77 \mathrm{E}-06$ \\
\hline 2 & 0.0012 & 0.0011 & $8.55 \mathrm{E}-06$ \\
\hline 3 & 0.0031 & 0.0040 & 0.0001 \\
\hline 4 & 0.0045 & 0.0064 & 0.0007 \\
\hline 5 & 0.0069 & 0.0107 & 0.0045 \\
\hline 6 & 0.0076 & 0.0184 & 0.0468 \\
\hline 7 & 0.0372 & 0.1027 & 0.6247 \\
\hline 8 & 4.5728 & 4.9593 & 8.2535 \\
\hline 9 & 78.7132 & 81.732 & 75.1352 \\
\hline
\end{tabular}

TABLE IX. ASC - ENERGY DISTRIBUTION VALUES ( $\mathrm{P}_{\mathrm{I}}$ ).

\begin{tabular}{|c|c|c|c|}
\hline $\begin{array}{c}\text { Decomposition } \\
\text { Scale }\end{array}$ & $\begin{array}{c}\text { OFF State } \\
\text { Voltage }\end{array}$ & $\begin{array}{c}\text { ON State } \\
\text { Voltage }\end{array}$ & $\begin{array}{c}\text { ON State } \\
\text { Current }\end{array}$ \\
\hline 1 & $1.19981 \mathrm{E}-06$ & $1.15161 \mathrm{E}-06$ & $8.05324 \mathrm{E}-08$ \\
\hline 2 & $1.43977 \mathrm{E}-05$ & $1.26677 \mathrm{E}-05$ & $1.01706 \mathrm{E}-07$ \\
\hline 3 & $3.71941 \mathrm{E}-05$ & $4.60645 \mathrm{E}-05$ & $1.18955 \mathrm{E}-06$ \\
\hline 4 & $5.39914 \mathrm{E}-05$ & $7.37033 \mathrm{E}-05$ & $8.32684 \mathrm{E}-06$ \\
\hline 5 & $8.27868 \mathrm{E}-05$ & 0.000123223 & $5.35297 \mathrm{E}-05$ \\
\hline 6 & $9.11855 \mathrm{E}-05$ & 0.000211897 & 0.000556709 \\
\hline 7 & 0.000446329 & 0.001182707 & 0.007431109 \\
\hline 8 & 0.054864866 & 0.057111961 & 0.098179378 \\
\hline 9 & 0.94440805 & 0.941236625 & 0.893769576 \\
\hline
\end{tabular}

The WEE values are calculated for the OFF state voltage, the $\mathrm{ON}$ state voltage, and the $\mathrm{ON}$ state current signals for the BDC and ASC, respectively as follows:

$$
\begin{aligned}
& \left\{\begin{array}{l}
W E E_{U O F F}=0.31, \\
W E E_{U O N}=0.35, \\
W E E_{I O N}=0.39,
\end{array}\right. \\
& \left\{\begin{array}{l}
W E E_{U O F F}=0.32, \\
W E E_{U O N}=0.34, \\
W E E_{I O N}=0.53
\end{array}\right.
\end{aligned}
$$

By using WEE values, in order to interpret the contribution of the load, a new index called Flicker Contribution Ratio (FCR) can be described in (19)

$$
F C R=\left(\frac{W E E_{I O N}-W E E_{U O F F}}{W E E_{I O N}}\right) \times 100 .
$$

Since the WEE represents the amount of information and is expressed in bits, the WEE values for the voltage and the currents signal can be used together in the equation. $W E E_{U_{O F F}}$ includes the flicker effect of the remaining power system and $W E E_{I_{O N}}$ includes the flicker effect of the load and background system. Thus, the flicker contribution ratio of the load can be obtained as defined in (19).

By using this equation, the FCR of the BDC and ASC are then calculated respectively, as follows:

$$
\begin{aligned}
& F C R=\left(\frac{0.39-0.31}{0.39}\right) \times 100=20.51 \\
& F C R=\left(\frac{0.53-0.32}{0.53}\right) \times 100=39.62
\end{aligned}
$$

The FCR value for BDC states that the $20.51 \%$ of the overall flicker disturbance is caused by BDC and $79.49 \%$ comes from the background power systems. In the same manner, the FCR value for ASC states that the $39.62 \%$ of the overall flicker disturbance is caused by ASC and $60.38 \%$ comes from the background power systems. The FCR value of the ASC is higher than the FCR value of the BDC as expected. This is due to the main load in the ASC being EAF, which generates more voltage fluctuation when compared to the LFs in BDC. The results are tabulated as given in Table $X$.

\begin{tabular}{|c|c|c|}
\hline \multicolumn{1}{|c|}{ TABLE X. FCR RESULTS FOR BDC AND ASC. } \\
\begin{tabular}{|c|c|c|}
\hline & Load & $\begin{array}{c}\text { Background } \\
\text { Power Sytem }\end{array}$ \\
\hline BDC & $20.51 \%$ & $79.49 \%$ \\
\hline ASC & $39.62 \%$ & $60.38 \%$ \\
\hline
\end{tabular}
\end{tabular}

\section{DISCUSSION}

By using FCR index, the main source for flicker can be easily addressed and the possible conflict between power system operators and users can be settled. Moreover, the proper interpretation of flicker contribution level helps on identification of the most feasible solution for flicker disturbance, and thus, corrective measures such as SVC, STATCOM can be applied accordingly.

According to the local regulations and directives, power system users like BDC and ASC should comply with flicker compatibility limits. In order to comply with these limits, the users should install flicker compensation systems such as SVC and STATCOM. But it is not easy and completely true to decide the correct flicker compensation solution considering only the results of the IEC 61000-4-15 flicker meter as mentioned in Section I. Without taking into account the real contribution level, the only solution for flicker disturbance seems as STATCOM. But STATCOM is really expensive compared to SVC and in some cases, it is not really necessary to use STATCOM. The above obtained FCR values for BDC and ASC provides the better understanding about their flicker responsibilities and thereby, the most feasible investment e.g. SVC can be made by the owners of BDC and ASC. Although the flicker compensation performance of SVC is low compared to STATCOM, when the results of the IEC flicker meter is multiplied with FCR value, the compatibility level can be reached by SVC solution.

\section{CONCLUSIONS}

The flicker measurements are performed according to a flicker meter defined in the IEC 61000-4-15. The main drawback of this meter is having only a voltage signal input, and it is not sufficient to interpret the responsibility of the load and remaining power systems separately. Since the voltage at the measurement point might include the background flicker effect, it will not be fully accurate to 
interpret the flicker responsibility of the installation considering the results of this flicker meter directly. Therefore, in order to get a better understanding of the individual flicker contribution, it is necessary to perform a comprehensive analysis of the flicker. This paper proposes new approaches to investigate the flicker characteristics by using the sampled data taken from the EAF and LFs. The sampled data were obtained from real on-site measurements performed in two different iron and steel factories. The new approaches are given by using statistical methods, spectral analysis, and multi-resolution wavelet analysis, which have not been applied together for the flicker evaluation in the literature before. Finally, a new index is proposed to define the flicker contribution of the load.

According to the results of SNR values and the comparison of histograms for the On and Off state, it is shown that some important information regarding the flicker can be obtained from the flicker frequency range of the signal. This is true in particular for the higher amplitudes in the flicker frequency range during the On State in the spectrograms that prove that some paramount information can be extracted from the signal.

With the help of MRA, the coefficients corresponding to the flicker frequency range are obtained and processed. In addition to the voltage samples, the coefficients obtained from the current signals are used in the analysis. To extract the amount of information in the voltage and current signals, the wavelet energy entropy values are calculated. Then, a new index called Flicker Contribution Ratio is proposed using the information theory based wavelet energy entropy. The FCR represents the percentage flicker disturbance contribution of the load. The FCR values of BDC and ASC are obtained $20.51 \%$ and $39.62 \%$, respectively. The FCR value of ASC is greater than BDC. Due to the nonlinear fluctuating current characteristics of the EAF in ASC, it generates more voltage fluctuations and flicker frequency components at the PCC. It proves that proposed FCR index provides the proper interpretation for the main flicker source detection and the flicker responsibility percentage of each load.

\section{REFERENCES}

[1] Testing and measurement techniques - Power quality measurement methods, IEC Std. 61000-4-30, 2009.

[2] Flickermeter - Functional and design specifications, IEC Std. 610004-15, 2011.

[3] Part: 3-7: Limits - Assessment of emission limits for the connection of fluctuating installations to $M V, H V$, and $E H V$ power systems, IEC Std. 61000-3-7, 2008.

[4] IEEE Recommended practice for measurement and limits of voltage fluctuations and associated light flicker on AC power systems, IEEE Std. 1453-2015.

[5] P. G. V. Axelberg, M. H. J. Bollen, I. Y. H. Gu, "A measurement method for determining the direction of propagation of flicker and for tracing a flicker source", 18th Int. Conf. Electricity Distribution, 2005, pp. 505-508. DOI: 10.1049 /cp:20051093.

[6] P. G. V. Axelberg, M. H. J. Bollen, "An algorithm for determining the direction to a flicker source", IEEE Trans. Power Del., vol. 21, no. 2, pp. 775-760, 2006. DOI: 10.1109/TPWRD.2005.861227.

[7] P. G. V. Axelberg, M. H. J. Bollen, I. Y. H. Gu, "Trace of flicker sources by using the quantity of flicker power", IEEE Trans. Power Del., vol. 23, no. 1, pp. 465-471, 2008. DOI: 10.1109/TPWRD.2007.905565.
[8] M. Poormonfaredazimi, H. Moghadam, A. Doroudi, "A novel method to trace flicker sources", in Proc. 17th Conf. Electrical Power Distribution Networks (EPDC), Tehran, Iran, 2012, pp. 1-7.

[9] N. F. Jamaludin, A. F. Abidin, "Flicker power algorithm based on Fast Fourier Transform (FFT) demodulation", IEEE 3rd Int. Conf. System Engineering and Technology (ICSET), Shah Alam, Malaysia, 2013, pp. 252-257. DOI: 10.1109/ICSEngT.2013.6650180.

[10] N. F. Jamaludin, A. F. Abidin, "The used of Fast-Fourier Transform (FFT) demodulation for flicker source identification", 2014 IEEE 8th Int. Power Engineering and Optimization Conf., Langkawi, Malaysia, 2014, pp. 537-542. DOI: 10.1109/PEOCO.2014.6814487.

[11] A. F. Payam, B. M. Dehkordi, M. S. Sadri, M. Moallem, "An energy method for determination of flicker source at the point of common coupling", Int. Conf. Computer as a Tool (EUROCON 2007), Warsaw, Poland, 2007, pp. 1615-1620. DOI: 10.1109/EURCON.2007.4400457.

[12] Z. Shao, D. Wu, R. Zhang, J. Kang, "Application of flicker source location system in Fujian grid", Asia-Pacific Power and Energy Engineering Conf. (APPEEC 2010), Chengdu, China, 2010. DOI: 10.1109/APPEEC.2010.5448126.

[13] E. Altintas, O. Salor, I. Cadirci, M. Ermis, "A new flicker contribution tracing method based on individual reactive current components of multiple EAFs at PCC", IEEE Trans. Ind. Appl., vol. 46, no. 5, pp. 1746-1754, 2010. DOI 10.1109/TIA.2010.2058835.

[14] A. B. Nassif, E. E. Nino, W. Xu, "A V-I slope-based method for flicker source detection", in Proc. 37th Annual North American Power Symposium, Ames, Iowa, USA, 2005, pp. 364-367. DOI: 10.1109/NAPS.2005.1560560.

[15] T. Tayjasanant, W. Xu, "A case study of flicker interharmonic problems caused by a variable frequency drive", 11th Int. Conf. Harmonics and Quality of Power, 2004, pp. 72-76. DOI: 10.1109/ICHQP.2004.1409331.

[16] D. Zhang, W. Xu, A. Nassif, "Flicker source identification by interharmonic power direction", Canadian Conf. Electrical and Computer Engineering, Saskatoon, Canada, 2005, pp. 549-552. DOI: 10.1109/CCECE.2005.1556990

[17] T. Zheng, E. B. Makram, "Wavelet representation of voltage flicker", Electric Power Systems Research, vol. 48, no. 2, pp. 133-140, 1998. DOI: 10.1016/S0378-7796(98)00099-6.

[18] S. J. Huang, C. T. Hsieh, "Application of continuous wavelet transform for study of voltage flicker-generated signals", IEEE Trans. Aerosp. Electron. Syst, vol. 26, no. 3, pp. 925-932, 2000. DOI: $10.1109 / 7.869511$.

[19] M.-T. Chen, A. P. S. Meliopoulos, "A hybrid digital algorithm for harmonic and flicker measurement", in Proc. IEEE Power Engineering Society Transmission and Distribution Conf., 2002, pp. 1488-1493. DOI: 10.1109/PESW. 2002.985271.

[20] Y. Onal, U. C. Turhal, "The orthogonal Hilbert-Huang transform application in voltage flicker analysis", 4th Int. Conf. Power Engineering, Energy \& Electrical Drives, Istanbul, Turkey, 2013, pp. 700-704. DOI: 10.1109/ PowerEng.2013.6635695.

[21] J. K. Taylor, C. Cihon, Statistical Techniques for Data Analysis, $2^{\text {nd }}$ Ed., USA: Chapman \& Hall/CRC, 2004, p. 33.

[22] S. Seker, T. C. Akinci, S. Taskin, "Spectral and statistical analysis for ferroresonance phenomenon in electric power systems", Electrical Engineering, vol. 94, no. 2, pp. 117-124, 2012. DOI: 10.1007/s00202-011-0224-4.

[23] L. Debnath, Wavelet Transforms and Their Applications, Boston, USA: Springer Science+Business Media, LLC, 2002, pp. 258-263.

[24] L. Debnath, Wavelet Transforms and Time-Frequency Signal Analysis, Boston, USA: Springer Science+Business Media, LLC, 2001, pp. 332-333.

[25] R. A. Gopinath, C. S. Burrus, "Wavelet transforms and filter banks", Wavelets: A Tutorial in Theory and Applications, vol. 2, pp. 603-654, 1992. DOI: 10.1016/B978-0-12-174590-5.50024-1.

[26] S. G. Mallat, "A theory for multiresolution signal decomposition: the wavelet representation", IEEE Trans. Pattern Anal. Mech. Intelligent, vol. 11, no. 7, pp. 674-693, 1989. DOI: 10.1109/34.192463.

[27] S. Wang, T. Bi, K. Jia, "Wavelet entropy based fault detection approach for MMC-HVDC lines", IEEE Power \& Energy Society General Meeting, 2015, pp. 1-5. DOI 10.1109/PESGM.2015.7286582.

[28] S. Chen, H. Y. Zhu, "Wavelet transform for processing power quality disturbances", EURASIP Journal on Advances in Signal Processing, 2007. DOI: $10.1155 / 2007 / 47695$. 